UDC 291.1

LBC 86.201

\title{
MASS DISTANCE LEARNING AS A GLOBAL SOCIAL EXPERIMENT TO DIVIDE PEOPLE ${ }^{1}$
}

\author{
Andrey I. Makarov \\ Volgograd State University, Volgograd, Russian Federation
}

\begin{abstract}
The article analyzes the problems of education that have worsened during the crisis associated with the pandemic. This is a large complex of problems that threaten not only the development, but also the existence of the education system in Russia. These are methodological problems: the lack of methods and the necessary material and technical base for the implementation of the distance format of mass education. The problems of forming the motivational potential of participants in the educational process, which is very relevant in the conditions of the beginning of the degradation of the education system under the pressure of its bureaucratization. This is a problem of increasing the volume of independent work of students and schoolchildren, which is not provided for by the methods of full-time education. The author draws on Nassim Taleb's concept of "the dictatorship of the small minority". Nassim Taleb claims that the theory of "the dictatorship of the small minority" is quite applicable to such a social institution as science. The minority dictatorship promotes the expanded accelerated digitalization of the education system. This entails stimulating the transformation of society, the transition from an individualized society to a dividualized society. Distance learning should be only a part of education and should be introduced very carefully at the last stages of higher education and in the system of additional education. This thesis is proved in this article. The author concludes that ignoring the problems discussed in the article can lead to a catastrophe of the education system in Russia.
\end{abstract}

Key words: philosophy of education, pandemic, distant learning, crisis, individualized society.

Citation. Makarov A.I. Mass Distance Learning as a Global Social Experiment to Divide People. Logos et Praxis, 2021, vol. 20, no. 1, pp. 31-35. (in Russian). DOI: https://doi.org/10.15688/lp.jvolsu.2021.1.4

УДК 291.1

ББК 86.201

\section{МАССОВОЕ ДИСТАНЦИОННОЕ ОБУЧЕНИЕ КАК ГЛОБАЛЬНЫЙ СОЦИАЛЬНЫЙ ЭКСПЕРИМЕНТ ПО РАЗОБЩЕНИЮ ЛЮДЕЙ ${ }^{1}$}

\author{
Андрей Иванович Макаров \\ Волгоградский государственный университет, г. Волгоград, Российская Федерация
}

\begin{abstract}
Аннотация. В статье анализируются проблемы образования, обострившиеся во время кризиса, связанного с пандемией. Это большой комплекс проблем, угрожающий не только развитию, но и существованию системы образования в России. Это проблемы методического характера: отсутствие методик и необходимой материально-технической базы для осуществления дистанционного формата массового обучения. Проблемы формирования мотивационного потенциала участников образовательного процесса, очень актуальной $\vec{\sim}$ в условиях начавшейся деградации системы образования под прессом ее бюрократизации. Это проблема ฮิ увеличения объема самостоятельной работы студентов и школьников, не предусмотренная методиками очного образования. Автор опирается на концепт Нассима Талеба «диктатура меньшинств». Нассим Талеб ४ утверждает, что теория «диктатуры меньшинства» вполне применима к такому социальному институту как о̊ наука. Диктатура меньшинства продвигает расширенную ускоренную цифровизацию системы образован. ния. Это влечет за собой стимулирование трансформации общества, переход от индивидуализированного общества к дивидизированному обществу. Дистанционное обучение должно быть лишь частью образован. ния и вводиться очень осторожно на последних ступенях высшего образования и в систему дополнительного
\end{abstract}


образования. Этот тезис обосновывается в данной статье. Автор делает вывод, что игнорирование рассмотренных в статье проблем может привести к катастрофе системы образования в России.

Ключевые слова: философия образования, пандемия, дистанционное обучение, кризис, индивидуализированное общество.

Цитирование. Макаров А. И. Массовое дистанционное обучение как глобальный социальный эксперимент по разобщению людей // Logos et Praxis. -2021. - T. 20, № 1. -C.31-35. - DOI: https://doi.org/10.15688/lp.jvolsu.2021.1.4

Вынужденный переход во время самоизоляции на массовое дистанционное обучение стал глобальным социальным экспериментом, результаты которого уже необходимо осмыслять разным научным дисциплинам. Это актуально в связи с тем, что быстро выявленная родителями и педагогами опасность профанации образования на дистанте привела к многотысячным протестам родителей по всей стране [Родители против... web]. Ситуацию в высшей школе исследовал коллектив авторов, который в октябре 2020 г. подготовил аналитический доклад «Высшее образование: уроки пандемии: оперативные и стратегические меры по развитию системы», выполненный коллективами тринадцати российских университетов. При анализе этого текста бросается в глаза наличие большого количества логических противоречий между выводами (рекомендациями) и статистическими данными, приведенными в исследовании. Обращу внимание только на одно из них, касающееся оценки введения массового дистанционного обучения. Так, в аналитическом докладе приводятся статистические данные о том, что « $88,2 \%$ преподавателей скептически относятся к формату дистанционного обучения, 42,7 \% считает, что электронный формат приведет через год к ухудшению качества высшего образования, 67 \% преподавателей не соглашаются с тем, что большинство занятий через год будет в онлайн-формате». При этом авторы признают, что даже после того, как вузы предприняли «серьезные усилия по адаптации ППС (53,2 \% преподавателей прошли за последние месяцы курсы по ведению онлайн-обучения)» процент отрицательно оценивающих дистанционную форму обучения для студентов снизился незначительно: «87,8 \% преподавателей утверждают, что все же их занятия лучше проводить в очном формате» [Высшее образование... web].

Несмотря на эти цифры, отражающие позицию подавляющего большинства педаго- гической национальной элиты, авторы доклада делают неправомерный вывод о том, что нужно продвигать «цифровизацию» в вузовское образование не только как дополнительное образование или смешенное для аспирантов (против чего никто не возражает), но и для студентов бакалавриата и магистратуры. Авторы доклада зачем-то произвели подмену понятий с «несогласия университетского большинства с внедрением дистанционного образования» на «неготовность ППС к прогрессивным технологиям». Это, в частности, видно по следующему пассажу в докладе: «Заметная часть профессорско-преподавательского состава, хотя и перешла в онлайн, но попрежнему остается не готовой к интеграции онлайн-инструментов и технологий в образовательные программы в долгосрочной перспективе» [Высшее образование... web].

Авторы доклада, являясь меньшинством, не только отвергают позицию большинство профессуры и преподавателей, но и обвиняют их в отсталости, прямо намекая регулятору на необходимость насильственного внедрения того педагогического инструмента, который отвергается 87,9\% профессионального сообщества. Вот, что они доносят регулятору, т.е. чиновникам Минобрнауки: «Вынужденный “всплеск” использования электронного обучения, с одной стороны, расширяет возможности обновления системы высшего образования, но, с другой стороны, в случае снижения активности регулятора и руководства вузов создает риски быстрого отката системы или даже усиления противодействия освоению цифровых инструментов и практик» [Высшее образование... web].

Возникает актуальный вопрос: под воздействием каких факторов сформировалась сегодняшняя модель непартнерских отношений цифрофилийского меньшинства с большинством вузовского сообщества? Этот вопрос является предметом этой статьи, посвященной философии образования. 
Итак, прямо говорится об огромных рисках и о несогласии большинства. И в то же время звучат обреченные нотки о том, что в России будет продолжено внедрение дистанционного обучения в школах и вузах. Но здесь, к сожалению, нет противоречия: педагоги, не принимая этого сценария будущего, не верят в то, что решения будут приниматься на основе мнения большинства, а считают, что реализуются планы внедрения смешенной формы, продвигаемой меньшинством. Собственно, эта выученная беспомощность некоторой части представителей большинства и является фактором, обеспечивающим напористую мотивацию цифрофилийского меньшинства. Термин «цифрофилийское меньшинство» произведен согласно «концепции диктатуры меньшинств», предложенной в качестве объяснительной модели специфики современной системы управления известным американским экономистом Нассимом Николасом Талебом [Талеб 2018]. Эта концепция вполне продуктивна для объяснения логики происходящих процессов в отечественной системе образования, процессов, подрывающих эту самую систему. В своей книге «Skin in the game. Hidden Asymmetries in Daily Life» Нассим Талеб предвидел то, свидетелями чего мы теперь являемся: насильственное внедрение инноваций меньшинством, обладающим напористостью и административным потенциалом. Это - набравшая силу тенденция последнего времени: диктатура меньшинств является следствием перехода от индивидуализированного общества к дивидизированному обществу. Индивидуализированное общество, о котором так своевременно писал Зигмунд Бауман, трансформируется в дивидизированное общество [Бауман 2002]. Этот феномен получил в западной философии имена «смерть Субъекта» и «смерть Человека». Индивид утрачивает такое свое качество как когнитивная автономия «я», при этом он не становится ни членом коллектива, ни элементом массы (в том смысле, в котором массы описали философы XX в.). Человек больше не частица, он - волна в потоке очень быстрых изменений, темп и ритм которых несоразмерны его сознанию и телу. Это новый феномен дивида, то есть атома, фатально разделенного с другими атомами. Пример дивидизации - это то, что мы - преподаватели - наблюдали при нахождении в Zoom во время своих лекций. Вы видите не студентов, а аватары или черные таблички, за которыми может никого не быть. Вы заходите на это кладбище картинок, как на какой-то спиритический сеанс и начинаете выкликать голоса из зазеркалья: «Мария, вы с нами? Петр, вы с нами?». Мы стали свидетелями глобальной симуляции участия, когда невозможно соучастие, остается лишь возможность присутствия образа при отсутствии субъекта. Студенты вместе с преподавателями во время этой нормализации дивидизации (реального социального разобщения) экспериментировали с увеличением дистанции не только физической, но именно социальной. Дистанциирование означает, по сути, именно сочиальную изоляцию, и указывает не просто на физическое дистанцирование, а именно на разрыв социальной ткани, на изоляцию людей друг от друга. Это происходит посредством внедрения в общение цифрового посредника. Сложное общение, обмен смысловыми энергиями, эффектом которого является формирование общества как солидарного организма, превращается в упрощенную коммуникацию, обмен информацией, значениями с обедненной смысловой энергией, эффектом которой является формирование набора социально фригидных функциональных сообществ или множеств дивидов, изолированных друг от друга. Такие выводы подтверждает Сергей Рукшин, профессор Государственного педагогического университета им. А.И. Герцена, который пишет: «В “дистанционном" я вижу разобщение, а значит - угрозу биологическому виду. И если речь об образовании, то особенно. Потому что дистант умножает воспитание на ноль. Воспитание не передается ни дистанционно, ни уколами в musculusgluteus, то есть в задницу. Оно передается только от человека к человеку» [Mатематик Сергей Рукшин... web]. Важный вопрос сегодня: есть ли вероятность, что при принятии стратегических решений в области политики образования в нашей стране субъект решений будет опираться на позицию цифрофилийского меньшинства или на позицию представителя педагогического большинства, которым является Сергей Рукшин, руководитель знаменитого «Матцентра» 
(Санкт-Петербургского Центра математического образования), учитель лауреатов Филдсовской премии Григория Перельмана и Станислава Смирнова?

При переходе от живого физического присутствия в аудитории к виртуальному присутствию на экране снижается эмоциональный посыл и пафос речи. Поэтому, для того, чтобы поддержать уровень пафоса в речи, лектору нужно на порядок увеличивать интенсивность пафоса. Мои наблюдения показывают, что преподаватели этого не делают, потому что нет ни опыта, ни желания этого делать. Это делают, например, те, кто работает на телевидении. Они это знают, от них этого требуют. К чему это приводит? Это приводит к ослаблению педагогического эффекта речи педагога. Речь становится менее захватывающей, и в таком случае надо перемещать акцент в сторону логоса. Но идеи тоже вырабатываются на основе эмоционального потенциала. Речь идет о важнейшей проблеме мотивации. Может ктото сегодня сказать, что в среднем у российских студентов высокая мотивация к самостоятельному обучению? Вопрос этот риторический. Исследования показывают, что основной тип мотивации на 1-3 курсе- потребительскопроцессуальный, то есть студентам важен процесс обучения в коллективе. И только на 4 курсе возникает мотивация на результат [Мальцева, Суслова 2017, 67]. Это означает, что на 1-3 курсе удельный вес социализации очень велик, что дистантность, как форма слабых связей, чреватых разобщенностью людей, недопустима. Логичным было бы постепенное пилотное, а не ускоренное внедрение дистанционного обучения в вузах. Но меньшинство будет на настаивать на ускорении, что приведет к обрушению системы из-за ее нечеловекоразмерности. Случившийся глобальный кризис усилил тенденцию к утере здравого смысла инноваторами, что выражается в продвижении проектов нечеловекоразмерных систем. Массовый переход на дистанционное обучение показал, что у субъекта образовательного процесса есть определенная размерность, которая игнорируется представителями цифрофилийского меньшинства.

При этом очень важно подчеркнуть, что цифровизированные дистанционные образовательные системы вполне приемлемы для до- полнительного образования, так как у выпускников вузов сформировались навыки самоорганизации и мотив получать самообразование. У школьников и студентов бакалавриата нет еще этих способностей из-за их возрастных и поколенческих особенностей. Современная культура является фактором не концентрирующим, а рассеивающим внимание индивида, превращающим его в скролящего новостные ленты дивида. Поэтому дистантные технологии, предполагающие резкое увеличение времени и энергии на самообразование, расходятся с психоэмоциональной и организационной размерностью многих участников образовательного процесса.

Начавшийся процесс дивидиации общества в связи с построением нечеловекоразменных систем является симптомом того, что меньшинство, которое пытается управлять реальностью, потеряло с ней связь, что не может не проявляться в нарастании катастрофических событий. Нынешний глобальный социальный эксперимент по введению массового дистанционного обучения показал, что российские школы, колледжи и вузы не приняли этот вариант смешенного обучения. Однако при этом до сих пор нет официального признания фактического педагогического провала этого эксперимента. Это, по нашему глубокому убеждению, влечет увеличение рисков социальных катастроф, одна из которых катастрофа образовательной системы.

\section{ПРИМЕЧАНИЕ}

${ }^{1}$ Работа выполнена на базе Научно-образовательного центра ВолГУ «Человек в системе российских ценностей и институтов».

\section{СПИСОК ЛИТЕРАТУРЫ}

Бауман 2002 - Бауман 3. Индивидуализированное общество. М.: Логос, 2002.

Высшее образование... web - Высшее образование: уроки пандемии: оперативные и стратегические меры по развитию системы: аналитический доклад // http://www.tsu.ru/upload/iblock/ аналитический\%20доклад_для_МОН_итог 2020_.pdf(дата обращения: 28.02.2021).

Мальцева, Суслова 2017-Мальцева Л.В., Суслова Ю.А. Исследование мотивационной сферы студентов в процессе обучения в вузе // Вестник Кур- 
ганского государственного университета. 2017. № 3 (46). Вып. 9. С. 63-67.

Математик Сергей Рукшин... web- Математик Cергей Рукшин: «Опыт дистанционного образования провалился» [Санкт-Петербургские ведомости] // https://spbvedomosti.ru/news/ adaptation/matematik-sergey-rukshin-opytdistantsionnogo-obrazovaniya-provalilsya/ (дата обращения: 28.02.2021).

Родители против... web - Родители против дистанта. Онлайн-обучение нарушает права детей [AIF.RU] // https://krsk.aif.ru/society/roditeli_ protiv_distanta_onlayn-obuchenie_narushaet_ prava_detey.

Талеб 2018 - Талеб Н.Н. Рискуя Собственной Шкурой. Скрытая асимметрия повседневной жизни. М.: КоЛибри, Азбука-Аттикус, 2018.

\section{REFERENCES}

Bauman Z., 2002. Individualized Society. Moscow, Logos Publ.
Higher Education: Lessons of the Pandemic: Operational and Strategic Measures for the Development of the System: An Analytical Report. URL: http://www.tsu.ru/upload/iblock/ аналитический\%20report_for_MON itog2020_.pdf(accessed 28 February 2021).

Maltseva L.V., Suslova Yu.A., 2017 Research of the Motivational Sphere of Students in the Process of Studying at the University. Bulletin of the Kurgan State University, no. 3 (46), iss. 9, pp. 63-67.

Mathematician Sergey Rukshin: "The Experience of Distance Education failed". St. Petersburg vedomosti. URL: https://spbvedomosti.ru/news/ adaptation/matematik-sergey-rukshin-opytdistantsionnogo-obrazovaniya-provalilsya/ (accessed 28 February 2021).

Parents Against Distance. Online Learning Violates Children's Rights. AIF.RU. URL: https:// krsk.aif.ru/ society/roditeli_protiv_distanta_onlaynobuchenie_narushaet_prava_detey.

Taleb N. N., 2018. Risking His Own Skin. Hidden Asymmetry of Everyday Life. Moscow, KoLibri Publ., Azbuka-Atticus Publ.

\section{Information About the Author}

Andrey I. Makarov, Doctor of Sciences (Philosophy), Professor, Associate Professor, Department of Philosophy, Volgograd State University, Prosp. Universitetsky, 100, 400062 Volgograd, Russian Federation, socphil@volsu.ru, https://orcid.org/0000-0002-9056-3741

\section{Информация об авторе}

Андрей Иванович Макаров, доктор философских наук, профессор, доцент кафедры философии, Волгоградский государственный университет, просп. Университетский, 100, 400062 г. Волгоград, Российская Федерация, socphil@volsu.ru, https://orcid.org/0000-0002-9056-3741 